URL de la revista: https://revistas.uca.es/index.php/cifa

\title{
La colección de M. J. Jiménez Cisneros, un fondo por explorar
}

\author{
Antonio Ruiz Castellanos \\ Profesor Titular de la Universidad de Cádiz \\ antonio.ruizcastellanos@uca.es
}

ORCID: http://orcid.org/0000-0002-9290-3703

\begin{abstract}
Resumen: El Archivo de la Universidad de Cádiz se honra con el depósito del Fondo arqueológico de $\mathrm{M}^{\mathrm{a}}$ Josefa Jiménez Cisneros donado por su familia, fondo que merece ser conocido por arqueólogos, historiadores de la Antigüedad y epigrafistas de época romana y fenicio-púnica de la cultura gaditana. Las líneas de investigación y aportaciones de M. J. Jiménez Cisneros no han sido todavía suficientemente explotadas. Por otro lado, la historia de la Arqueología gaditana de los años cuarenta a los setenta del pasado siglo tiene también en estos fondos documentos e indicios importantes de la actividad desempeñada en la provincia.
\end{abstract}

Palabras clave: Fondo arqueológico, Mª Josefa Jiménez Cisneros, Arqueología, Historia de la Antigüedad, Epigrafía, Época romana y fenicio-púnica de la cultura gaditana, Historia de la Arqueología gaditana de los años cuarenta a los setenta del pasado siglo.

\section{The collection of M. J. Jiménez Cisneros, an archaeological fund to be explored}

ABSTRACT: The Archive of the University of Cádiz is honored with the deposit of the Archaeological Fund of $\mathrm{M}^{\mathrm{a}}$ Josefa Jiménez Cisneros donated by her family, a fund that deserves to be known by archaeologists, historians of Antiquity and epigraphists of the Roman and Phoenician-Punic times of Gadir/Gades. The lines of research and contributions of M. J. Jiménez Cisneros have not yet been sufficiently exploited. The history of the Archeology since the forties to the seventies of the last century also has in these funds important documents of its activity in Cádiz. 
Keywords: Archaeological Fund, $\mathrm{M}^{\mathrm{a}}$ Josefa Jiménez Cisneros, Interest for archaeologists, History of Antiquity, Latin and Phoenician-Punic Epigraphy of Gadir/Gades, History of the Archeology of Cádiz since the forties to the seventies of the last century.

\section{TRAYECTORIA PROFESIONAL}

El Archivo de la Universidad de Cádiz se honra con la donación por su familia del Fondo arqueológico de $\mathrm{M}^{\mathrm{a}}$ Josefa Jiménez Cisneros. ${ }^{1}$ Como es conocido, fue $\mathrm{M}^{\mathrm{a}}$ Josefa Jiménez directora de la Biblioteca de Temas Gaditanos del año 1974 al 1978, miembro del Instituto de Estudios Gaditanos e investigadora de la Historia y Arqueología de Cádiz y su provincia durante las décadas 1940-70.

Se trata de una mujer que se hizo a sí misma creándose un currículum investigador y arqueológico de nivel universitario, impensable para una mujer de aquel entonces. Comienza sus estudios en Cádiz en la Escuela Normal y en Bellas Artes; se licencia en Filosofía y Letras, Filología Clásica, en la Universidad Complutense de Madrid en 1948; al año siguiente es nombrada "delegada de excavaciones". Había participado y dirigido diversas excavaciones, especialmente la de Torre Alta (Puerto Real, Cádiz), cuyos resultados recoge en su tesis de doctorado, que llevaba por título Historia de Cádiz en la Antigüedad. Fue dirigida por el Dr. D. José Manuel Pabón y Suárez de Urbina, catedrático de Lenguas Clásicas en la universidad Complutense de Madrid. A partir del 12 de Diciembre del 49 ejerció como Comisaria local de Excavaciones, en sustitución de César Pemán, a las órdenes (y seguramente a propuesta) de J. Martínez Santa-Olalla, Comisario General de Excavaciones Arqueológicas con sede en Madrid, con quien mantiene frecuente correspondencia, a quien pide permisos y fondos, y le rinde cuentas, hasta que desapareció este cargo en $1955^{2}$.

Gracias a su posición como arqueóloga y a su conocimiento de idiomas (becada por el Institut Français de Madrid, fue profesora de francés en el instituto del Rosario de Cádiz), se relaciona con la flor y nata de la arqueología francesa ${ }^{3}$. Becada por el

\footnotetext{
${ }^{1}$ M.J. Jiménez Cisneros nació en Cádiz el 07/01/1916 y murió también en Cádiz el 10/11/2002. Su familia donó al Archivo de la UCA su colección de temas arqueológicos.

${ }^{2}$ M. Díaz Andreu y M. Ramírez Sánchez: La Comisaría General de Excavaciones Arqueológicas, Complutum 12, 2001, 325-343- La Arqueología española de campo había recibido la crítica de O.G.S. Crowford, Archaelogy in the field. Londres: Phoenix House, 1953: 210. J. Martínez Santa-Olalla había excluido a Obermaier ocupando su puesto. Varios arqueólogos españoles de prestigio presentaron un escrito ante Ruiz Jiménez, Ministro de Educación Nacional, en el que se quejaban del estado de la investigación arqueológica española y pedían la sustitución de la Comisaría por un Consejo de arqueólogos.

${ }^{3}$ Más que con la alemana, que fue dominante en España hasta el final de la Guerra Mundial.
} 
Consejo Superior de Investigaciones Científicas para una estancia en el Centre National de la Recherche Français (CNRF). Había colaborado con los profs. M. Gilbert y Charles Picard (profesor éste de Arqueología en la Sorbona), y con los Drs. G. Gaudron, A. Grenier y A. Varagnac en Paris. Fue invitada por la universidad de Monpellier para participar en las excavaciones que dirigía el profesor Gallet de Nanterre en Enverune. Imparte conferencias en estas facultades. "En Marsella realiza estudios sobre ánforas con los profesores Benoit y M. Rolland y los practica en Arlès en la excavación de la ciudad romana de Glanum. En París da conferencias sobre las excavaciones de Cádiz participando incluso en la TV. Estudia epigrafía fenicio-púnica con los profs. A. Dupond Sommer, Pflaum y J. G. Février" "4 se nota su preocupación por la escritura fenicio-púnica que estaba saliendo en sus excavaciones gaditanas.

Se mueve con sencillez y facilidad en Francia y en un mundo que entonces era privativo de los hombres ${ }^{5}$. Mantuvo correspondencia con profesores e investigadores del mayor rango también en España. Además de con su director de tesis, J.M. Pabón, con los profs. Santa Olalla, García Bellido, Pelayo Quintero, Tarradell, Pericot, DupontSommer, Cintas, Solé Sola, Thevenot y otros más. Entre los intelectuales gaditanos son amigos suyos Augusto Conte Lacave, Carlos Martel Biniegra, M. Martínez del Cerro, Benito Cuesta, Puelles y Puelles, Gener, César y José María Pemán, Concha Blanco entre otros.

Fue una viajera infatigable, en América viajó a la Antártida, con frecuencia visitó Indonesia y a juzgar por sus numerosas fotografías, también la zona subtropical de África.

$\mathrm{Su}$ función como delegada y comisaria de excavaciones le obliga a supervisar los distintos yacimientos. La vemos presente en varios escenarios arqueológicos de Cádiz y su provincia ${ }^{6}$. En Puerto Real en los Hornos fenicios del Pinar de Villanueva (excavación de 1951-52, planos del 120 al 146, 148, 152 y153); en el yacimiento de Torre Alta (láms. LXXXIII Y LXXXIV; XLI. LII, LIII, LVI, LIX, XCI, XCIV, XCVI, XCVIII y de

\footnotetext{
${ }^{4}$ Según nos comunica su sobrina la Dra. Carmen Jiménez.

${ }^{5}$ Es la tercera mujer nombrada comisaria local de Arqueología, tras Concepción Fernández-Chicarro y Francisca Jaúregui.

${ }^{6}$ Utilizamos las siguientes especificaciones: Láms. con números romanos para aquellos documentos que aparecen en su tesis de doctorado y que en el fondo M. J. Jiménez Cisneros del Archivo de la Universidad de Cádiz (AUCA) ocupan las 2 primeras cajas; los números arábigos corresponden a la caja 3, que contiene planos y mapas; y para las cajas siguientes la cifra primera de la caja va seguida de un guión correspondiente a la carpeta concreta. La caja 4 repite fotografías y láminas contenidas en las dos primeras cajas. La caja 5-1 contiene calcos de epigrafía. La 5-2, diapositivas sobre los diversos temas y yacimientos; la 5-3, microfilmes relativos a las distintas excavaciones. La caja 6 contiene fotografías de todos los temas; la 7-1: noticias de hallazgos comunicados a la Comisaría (el sobre va dirigido a Juan Vázquez Ortiz) sobre los diferentes yacimientos; de 7-2 a 7-11: anotaciones, apuntes y bibliografía usada; 7-12 entregas de material al Museo; de 7-13 a 7-17 apuntes, anotaciones y bibliografía. Hay disponibles en la Biblioteca de la UCA numerosas fotografías que han sido subidas por el Seminario "Agustín de Horozco"; algunas de ellas las he utilizado para ilustrar este texto.
} 
134 a 137); en el Olivar de los Valencianos ${ }^{7}$ (CI, CII, CIII, XIV), y en la finca Santo Domingo de la que describe el pavimento, opus spicatum (láms. XVI; 4-51 láms. LVIILVIII; 4-52 láms. XLIX con planos; y vasijas en 4-53). En Cádiz en el glacis de las Puertas de Tierra cerca de la cafetería Transvaal (planos del 115 al 119); en la Necrópolis Gaditana de Puertas de Tierra ${ }^{8}$; en Santa María del Mar (plano 112); en el instituto Nacional de Previsión (tumbas fenicias: cajas 4-8 y 4-9; plano 133); en la playa de Corona (excavada en nov. 1949; carpetas 4-4 y 4-5); en el hipogeo de la nueva Casa Cuna de Cádiz en el año 1950 (planos: 113, 122?, 124 y 4-6); en las obras de la casa González Santiago (año 1959, plano 147); en la prospección previa a la construcción del colegio de S. Felipe; en la finca El Bosque de Cádiz (propiedad de la familia Jiménez) y su entorno: S. Severiano (tumbas púnicas de la C/ Tolosa Latour en el año 1951; planos 156 y $164^{9}$ ); en el Cortijo de la Vela; en la playa de los Corrales; en la playa de la Caleta. En Asta Regia (campaña 1949-1950: horno romano, 159). En Baelo Claudia excavó parcialmente el teatro. En Puerto $S^{a}$ María, castillo de $S^{a}$ Catalina. En Rota, Puntilla del Salado (de la que se conservan planos en 7-16 y láms. LX y LXVIII en las carpetas 4-55 y 4-61); en Jerez en el Rancho de la Bola (sepulturas árabes, lám. CVII); en Medina Sidonia el Berrueco con cerámica de la E. Bronce; y otros hallazgos casuales (lám. CVIII); el horno cerámico de Barbate; en Santi Petri (ánforas 139-140); en el Cerro de los Mártires, S. Fernando; en Nuestra Señora de los Números (excavada por Cervera y Jiménez Alfaro por dimisión de Pelayo Quintero en el año 1923). Sobre N.S de los Números queda un cuaderno de campo redactado por ella en 7-7, (quizás su primer acercamiento a la arqueología).

Su tesis ha sido publicada con el título: Historia de Cádiz en la Antigüedad. Instituto de Estudios Históricos Gaditanos. Diputación Provincial. Jerez-Cádiz. 1971. El prólogo lo escribe el Almirante D. Eduardo Gener Cuadrado. Publicó también numerosos artículos sobre inscripciones de Gades: "Miscelánea epigráfica.

\footnotetext{
${ }^{7}$ López de la Orden, M. D.: "Hornos cerámicos romanos en el Olivar de los Valencianos (Puerto Real)", BMC, II, 1981, 59-62. R. Benítez Mota et al.: "Construcción y análisis funcional de un horno de tipología romana del ámbito de la Bahía de Cádiz”. AnMurcia, 27-28, 2011-2012, 543-552.

${ }^{8}$ Sobre el tema, Ana $\mathrm{M}^{\mathrm{a}}$ Niveau de Villedary y Mariñas Verónica Gómez Fernández (coords.). Las necrópolis de Cádiz. Apuntes de Arqueología gaditana en Homenaje a J.F. Sibón Olano. Servicio de publicaciones UCA. Cádiz 2010.

9 Muñoz Vicente, A. "Aportaciones al estudio de las tumbas de sillería prerromanas de Cádiz”, Boletín Museo de Cádiz, IV, 1983-84, pp. 47-54. Perdigones Moreno, L.; Muñoz Vicente, A. "Excavaciones arqueológicas de urgencia en un solar de la calle Tolosa Latour (Cádiz)", Anuario de Arqueología Andaluza, III (1987), Sevilla 1990, pp. 59-70. Archivo de la Delegación Provincial de la Consejería de Cultura de Cádiz. Actualización y Revisión del Inventario de Yacimientos Arqueológicos de Andalucía 1998. Necrópolis de la calle Tolosa Latour I-II, 1998.
}

DOI del artículo:

http://dx.doi.org/10.25267/Cuad investig fondos arch UCA.2019.i1 .06 
Inscripciones funerarias gaditanas inéditas”. Emerita 30 (1962), pp. 295 y sigs. Y otras publicaciones en la revista Germania ${ }^{10}$.

\section{MATERial ARQUeOLÓGico}

\subsection{Inscripciones romanas y alguna griega}

No sólo interesan sus lecturas en el caso de las ya desaparecidas, lecturas que pueden ser diferentes a otras publicadas, sino también el hecho de que ofrece el lugar de procedencia. Algunas están inéditas ${ }^{11}$ :

Imagen 1. Inscripción romana

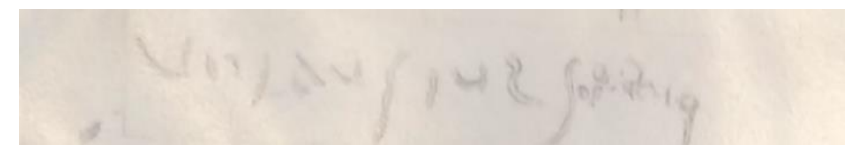

Fuente: Archivo de la Universidad de Cádiz (AUCA), C- 4-42 JC

\subsection{Marcas de alfarero}

Sobre todo las descritas y halladas por ella en el Pinar de Villanueva, donde "ha dado a conocer estructuras de hornos y depósitos de ánforas. Se han documentado ánforas del tipo Beltrán I y II-A, tégulas, restos de parrillas, ladrillos, restos de adobes y desechos de hornos cerámicos, fragmentos de cerámica con decoración y restos amorfos campanienses. Se han fechado en el s. I a.C.- II d. C."12. https://www.iaph.es/patrimonio-inmueble-andalucia/resumen.do?id=i4805.

Recoge las marcas de estas cerámicas (láms. XXVI, XLIV, XLV y XLVI; en 4-57 la lám. LIII). Muchas de ellas han sido calcadas en papel platina. ${ }^{13}$

10 Jiménez Cisneros: "Beobachtungen an ein Tapferbezirk bei Puerto Real, provinz Cádiz", Germania, 36, 1958, p.469-475.

${ }^{11}$ Ésta en 4-42. Hay otras que están desaparecidas o no reconocidas por estar rotas en varios trozos: EVTYCHIA / CARA DOMI/NAE AN XXX H/S.E.S.T.T.L.

12 Referencias bibliográficas en Carlos Alonso Villalobos. Prospección para la localización de yacimientos de producción anfórica de época romana. Cádiz. 1987, pp. 97-105. María Lazarich González. Informe preliminar de la primera campaña del proyecto de prospección arqueológica sistemática de la campiña sur gaditana: Término de Puerto Real. 1991, 98-100. Y también de la misma. Prospección arqueológica superficial de la campiña sur gaditana: Término de Puerto Real. 1991, pp. 89-97. Finalmente, Archivo Central de la Consejería de Cultura. Inventario de yacimientos arqueológicos de la Provincia de Cádiz. Pinar de Villanueva, 1987. Archivo Central de la Consejería de Cultura. S. Fernández Cacho, Inventario de yacimientos arqueológicos de la Provincia de Cádiz. Pinar de Villanueva, 1992.

${ }^{13}$ Además de las que describe en su tesis de la lám. LXXIV a la LXXIX, la caja 5-1 contiene calcos de epigrafía romana y fenicio-púnica. 
Imagen 2. Marcas de cerámica en papel platina

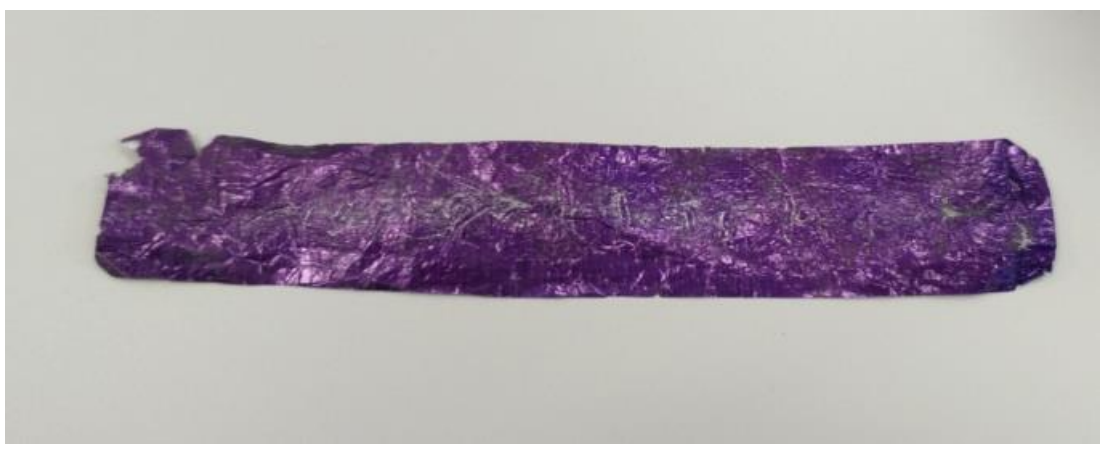

Fuente: Archivo de la Universidad de Cádiz (AUCA), C- 5-1 JC

Imagen 3. Dibujos de marcas de alfarero

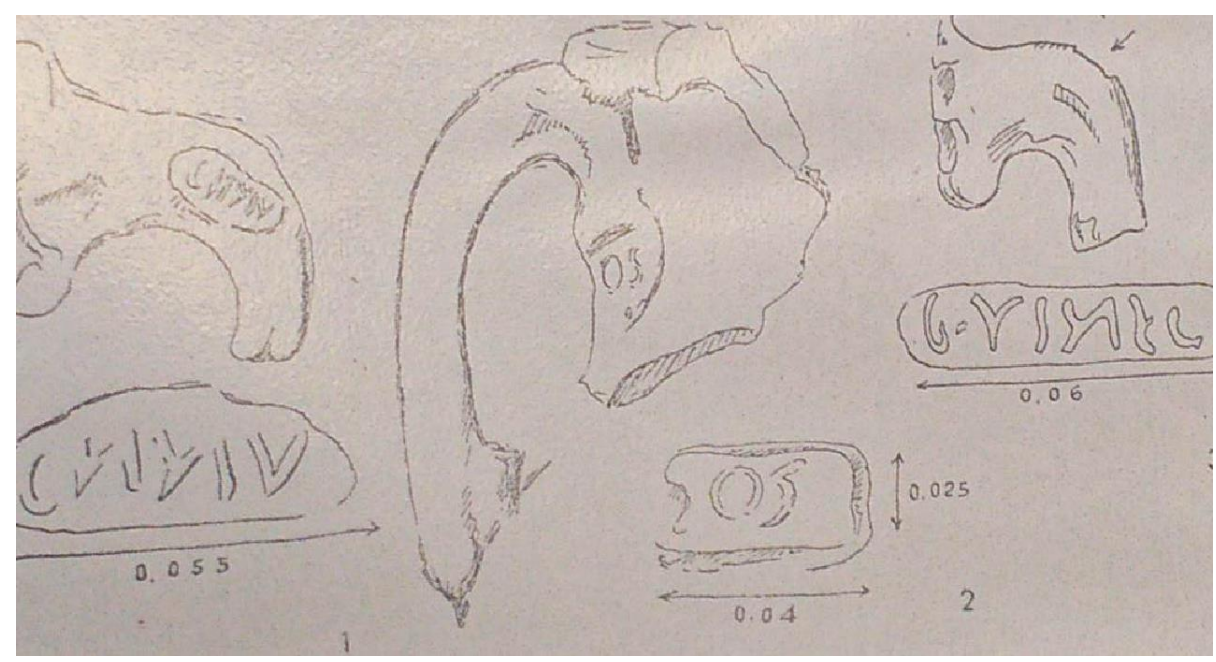

Fuente: Archivo de la Universidad de Cádiz (AUCA), C-4-57 JC

Recoge también las de Suárez de Salazar, Grandezas p. 147 (tomadas a su vez de Clemente). Y otras halladas al hacer el foso del Gran Teatro (Falla).

\subsection{Vasijas, vasos $^{14}$ :}

Las ánforas de Villanueva las ha fotografiado numerosas veces.

${ }^{14}$ García Vargas, E. La producción de ánforas en la bahía de Cádiz en época romana, Sevilla 1998. 
Imagen 4. Ánforas de la excavación del Pinar de Villanueva

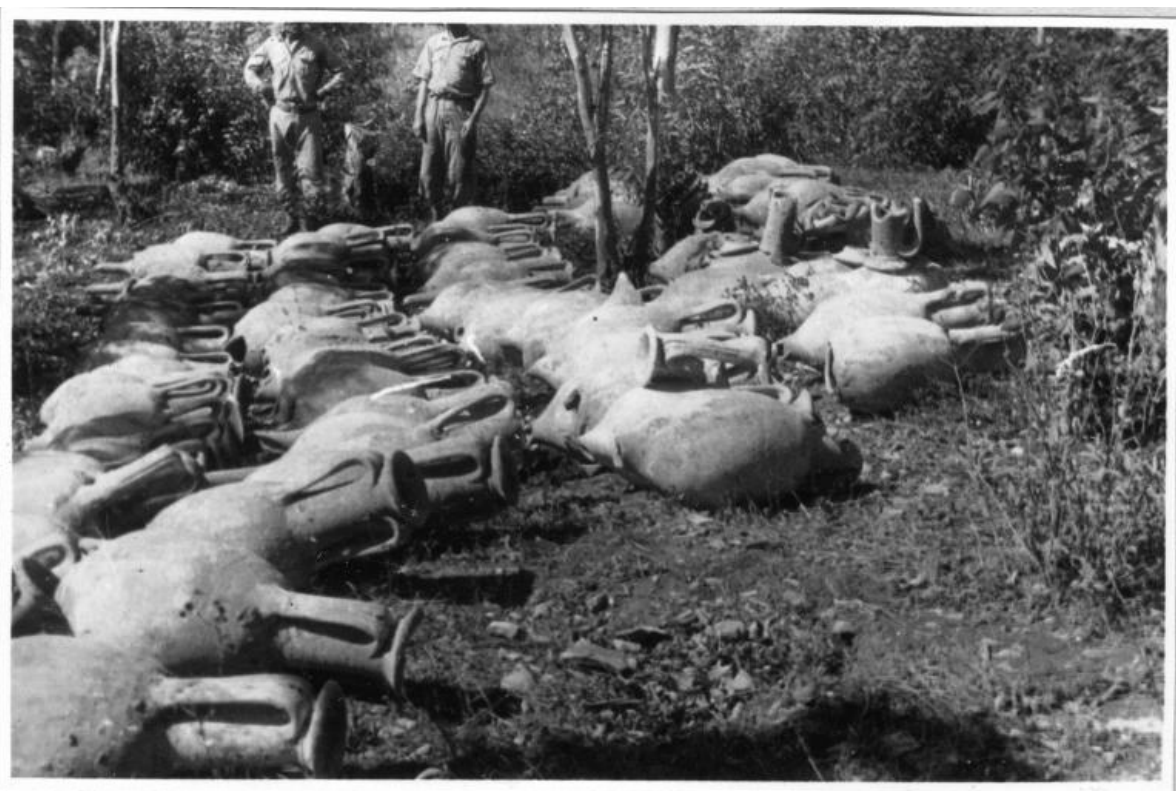

Fuente: Archivo de la Universidad de Cádiz (AUCA), C-2-72 J

O las de la Casa Cuna igualmente:

Imagen 5. Ánfora de la excavación de la Casa Cuna

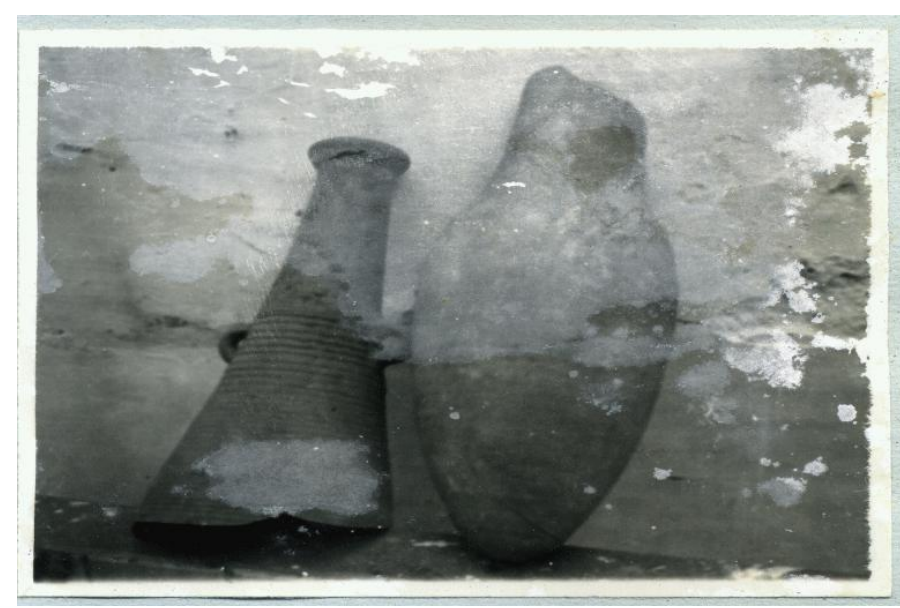

Fuente: Archivo de la Universidad de Cádiz (AUCA), C-1-48 JC

Sobre los glacis de Puerta de Tierra de Cádiz y la Necrópolis gaditana, en Patrimonio Inmueble de Andalucía $^{15}$; sobre la urna de alabastro (ver láms. XLVII; XLVIII).

Imagen 6. Urna de alabastro de la excavación de la Casa Cuna

15 https://www.iaph.es/patrimonio-inmueble-andalucia/resumen.do?id=i3444 Archivo de la Delegación Provincial de la Consejería de Cultura de Cádiz. Actualización y Revisión del Inventario de Yacimientos Arqueológicos de Andalucía 1998. Zona arqueológica Necrópolis de Cádiz, 1998.

DOI del artículo:

http://dx.doi.org/10.25267/Cuad investig fondos arch UCA.2019.i1 .06 


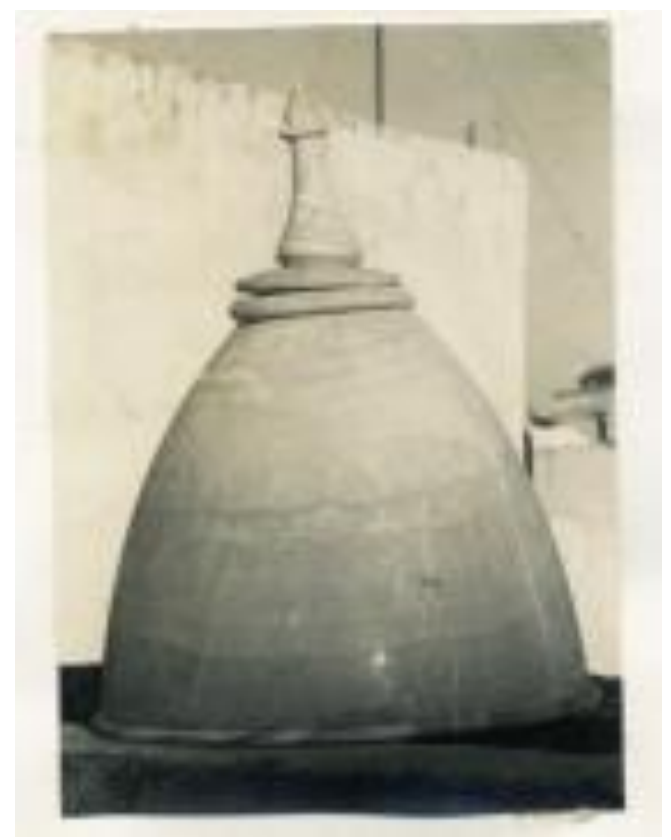

Fuente: Archivo de la Universidad de Cádiz (AUCA), C-4-34 JC

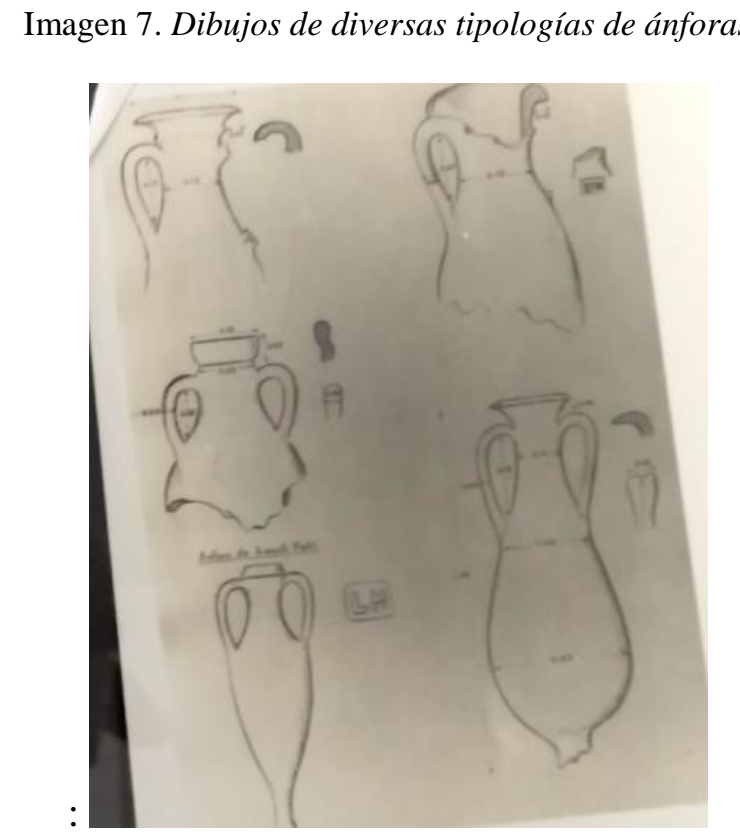

Fuente: Archivo de la Universidad de Cádiz (AUCA), C-3-139 JC 
Imagen 8. Vasija que se encuentra en el Museo de Cádiz

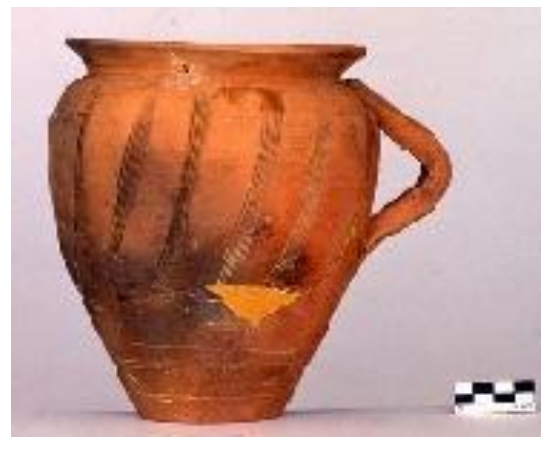

Fuente: Museo de Cádiz, inv. CE10437

La tipología de los vasos, que fotografía, debería quizás contrastarse con las "Cerámicas fenicio-púnicas de origen submarino del área de la Caleta" de Ángel Muñoz Vicente, Ferrer Albelda, y A.M. Sáez Romero, et al. ${ }^{16}$

\subsection{Esculturas y figurillas}

En el Cerro de los Mártires, S. Fernando: Figurillas humanas con diversos peinados:

Imagen 9. Figurillas humanas de la excavación en Cerro de los Mártires

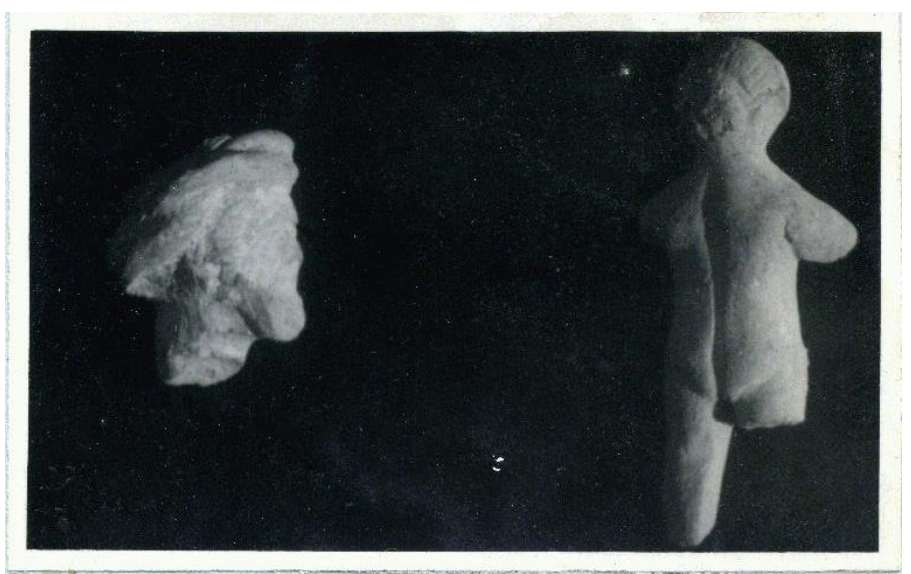

Fuente: Archivo de la Universidad de Cádiz (AUCA), C-1-41 JC

${ }^{16}$ Muñoz Vicente, A. "Las ánforas prerromanas de Cádiz”, Anuario Andaluz de Arqueología, II 1985, Sevilla 1987, pp. 471-478; y "Las cerámicas fenicio-púnicas de orígen submarino”, Cuadernos de Prehistoria y Arqueología Castellonenses, 15, (1991-1992), pp. 287-333. Ferrer Albelda, E. “Anotaciones sobre el taller cerámico de Gadir”, Boletín Museo de Cádiz, VII (1995-1996), pp. 63-76. A.M. Sáez Romero et al.: "Innovaciones, transformaciones y pervivencias. Evolución de la alfarería gadirita durante los ss. III-II a.n.e." En Actas del Congreso Internacional FIGLINAE BAETICAE. Talleres alfareros y producciones cerámicas en la Bética romana (ss. II a.C. - VII d.C.), Universidad de Cádiz, Noviembre 2003, B.A.R., int. ser., 1266, Oxford, 2004, pp. 413-426. Y A.M. Sáez Romero. Aproximación a la tipología de la cerámica común púnico-gadirita de los ss. III-II SPAL 14 (2005): 145-177.

DOI del artículo:

http://dx.doi.org/10.25267/Cuad investig fondos arch UCA.2019.i1

Editorial ad UCA .06 
Escarabeos; mascarillas y cánidos época púnica (láms. XXIV-XXV) del yacimiento del Instituto Nacional de Previsión: quizás en función de pebeteros ${ }^{17}$.

Imagen 10. Escarabeos del yacimiento del Instituto Nacional de Previsión

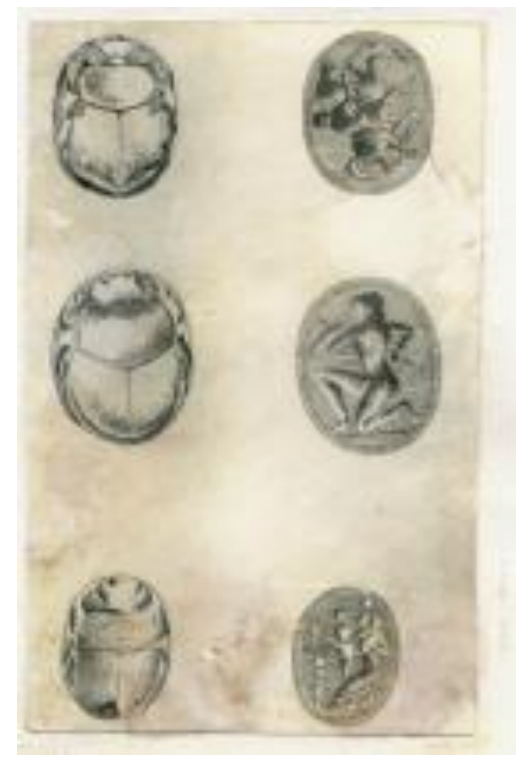

Fuente: Archivo de la Universidad de Cádiz (AUCA), C-1-21 JC

Imagen 11 y 12. Mascarilla y cánido púnicos del yacimiento del Instituto Nacional de Previsión

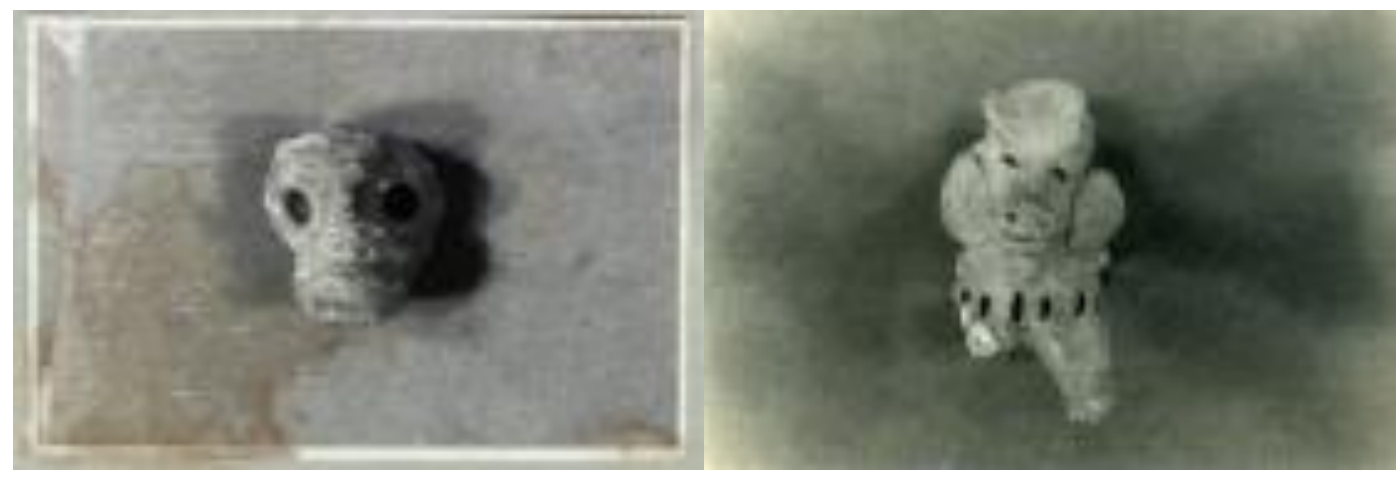

Fuente: Archivo de la Universidad de Cádiz (AUCA), C-1-24 y C-1-25 JC

${ }^{17} \mathrm{Al}$ estilo de las que presentan A. Ma Niveau y E. López Rosendo, Imitaciones de formas rituales tardopúnicas en el ámbito de la campiña gaditana. En Rui Morais, A. Fernández e M. J. Sousa (2014). As produçôes cerâmicas de imitaçâo na Hispania, Porto, 95-107.

DOI del artículo:

http://dx.doi.org/10.25267/Cuad investig fondos arch UCA.2019.i1

Editorial ad UCA .06 
Imagen 13. Objetos de época romana hallados en Medina Sidonia

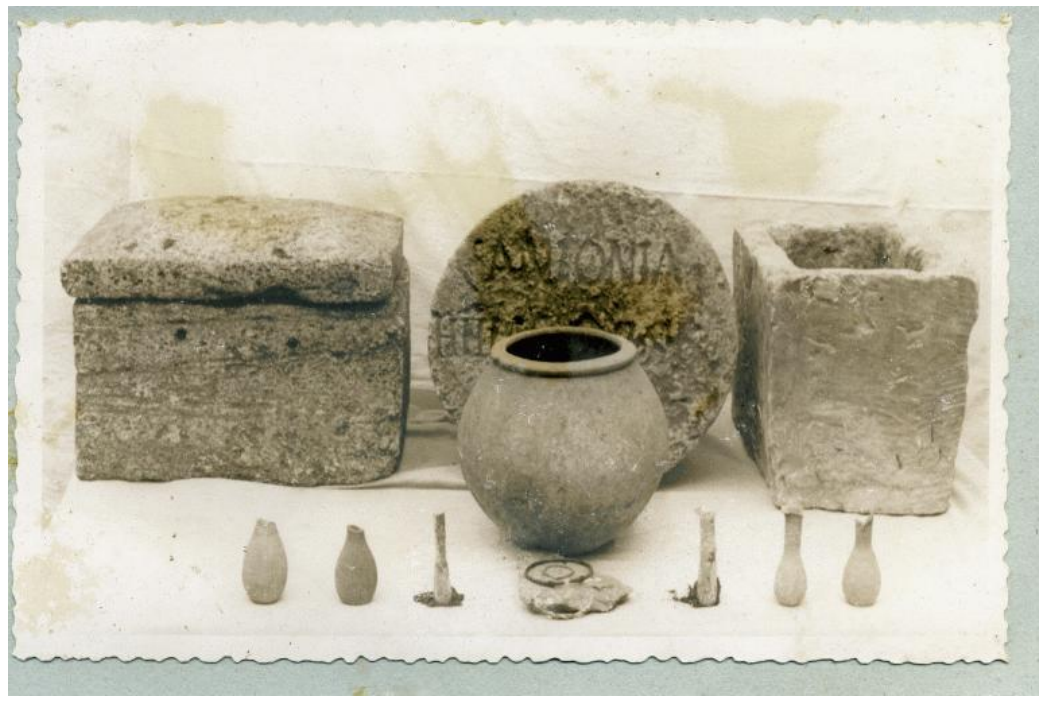

Fuente: Archivo de la Universidad de Cádiz (AUCA), C-2-108 JC

Imagen 14. Dibujos de estatuillas romanas de barro

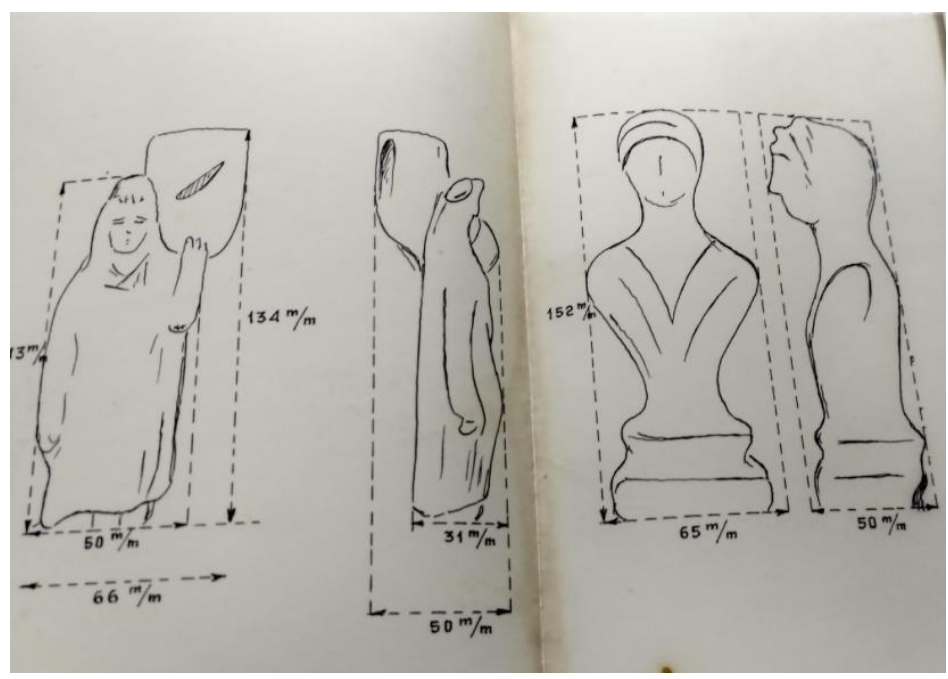

Fuente: Catálogo de la Biblioteca UCA. Colección Jiménez Cisneros Imagen 15. Dibujos de estatuillas romanas de barro 


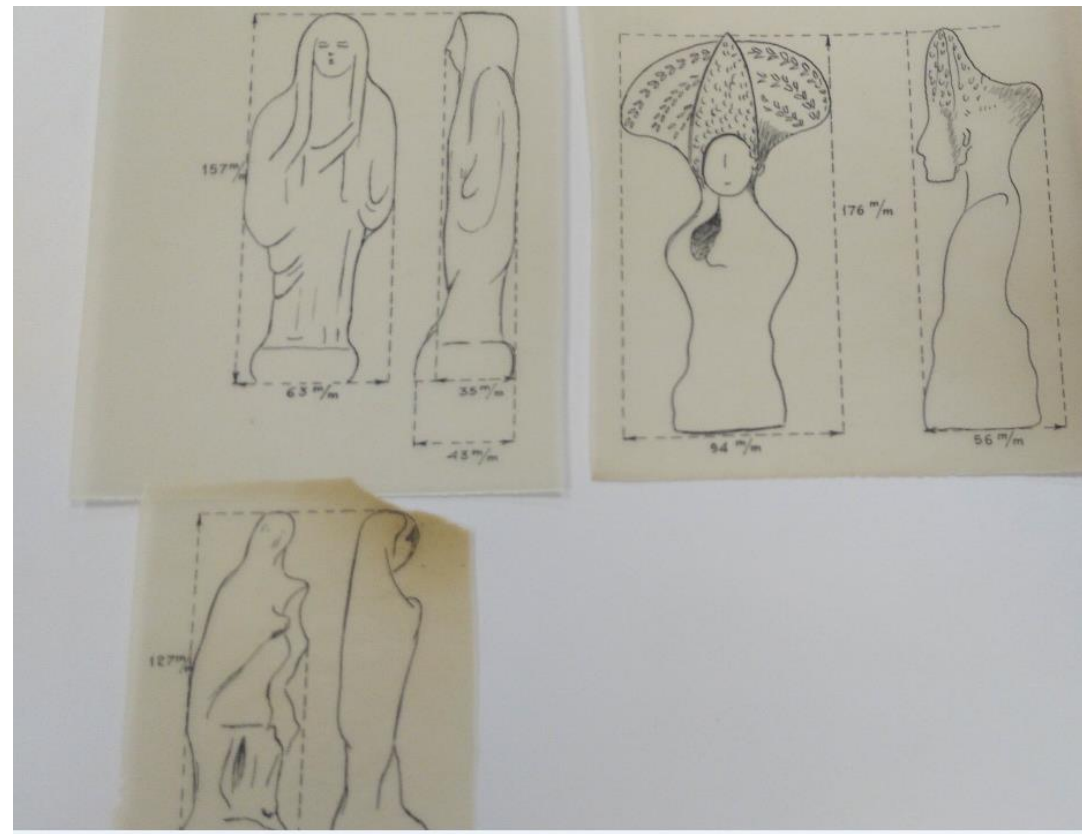

Fuente: Catálogo de la Biblioteca UCA. Colección Jiménez Cisneros

Ver lám. L del yacimiento del Glacis y playa de Santa María del Mar.

Son muy numerosas las fotografías: láms. de la XXI a XXIV; XLI ${ }^{18}$ (excepto barro Puntilla del Salado, Rota). Ver las cuentas, collares y anillos de la Necrópolis gaditana.

Imágenes 17, 18 y 19. Cuentas, collares y anillos de la Necrópolis gaditana (púnica y romana)
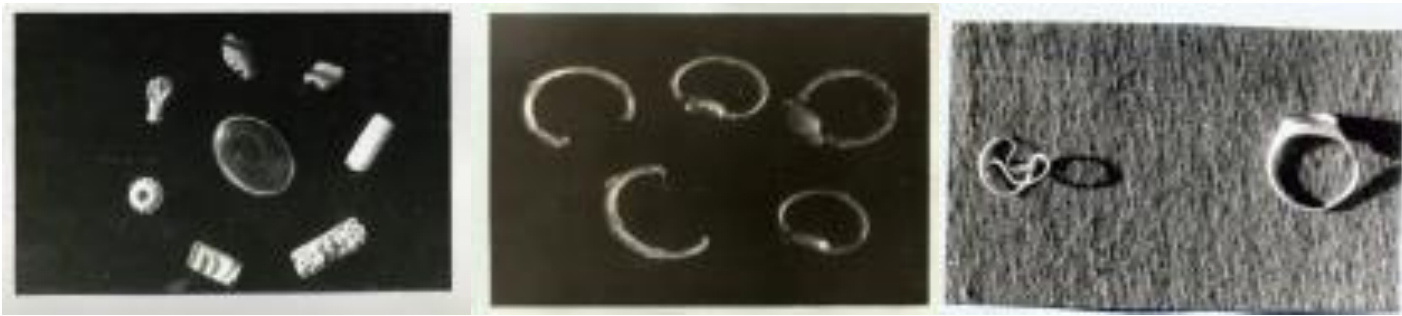

Fuente: Archivo de la Universidad de Cádiz (AUCA), C-1-38 JC y C-1-43(2) JC

${ }^{18}$ Cf. Bandera Romero, M. L. de la “Orfebrería gaditana: Técnicas y Tipología”, Boletín Museo de Cádiz, III (1981-82), Cádiz 1982, pp. 33-42. Perea Caveda, A. "La orfebrería púnica de Cádiz”, Aula Orientalis, III, 1-2, pp. 295-322, Barcelona 1985. Perea Caveda, A. "El taller de orfebrería de Cádiz y sus relaciones con otros centros coloniales e indígenas", Producciones artesanales fenicio-púnicas. VI Jornadas de Arqueología fenicio-púnica. (Ibiza 1991), Ibiza 1992, pp. 75-87. M.D. López de la Orden. La glíptica de la antigüedad en Andalucía, Cádiz, 1990.

DOI del artículo:

http://dx.doi.org/10.25267/Cuad investig fondos arch UCA.2019.i1

Editorial ad UCA .06 
Y la joya púnica más vistosa, procedente del yacimiento del Instituto Nacional de Previsión.

Imagen 20. Joya púnica

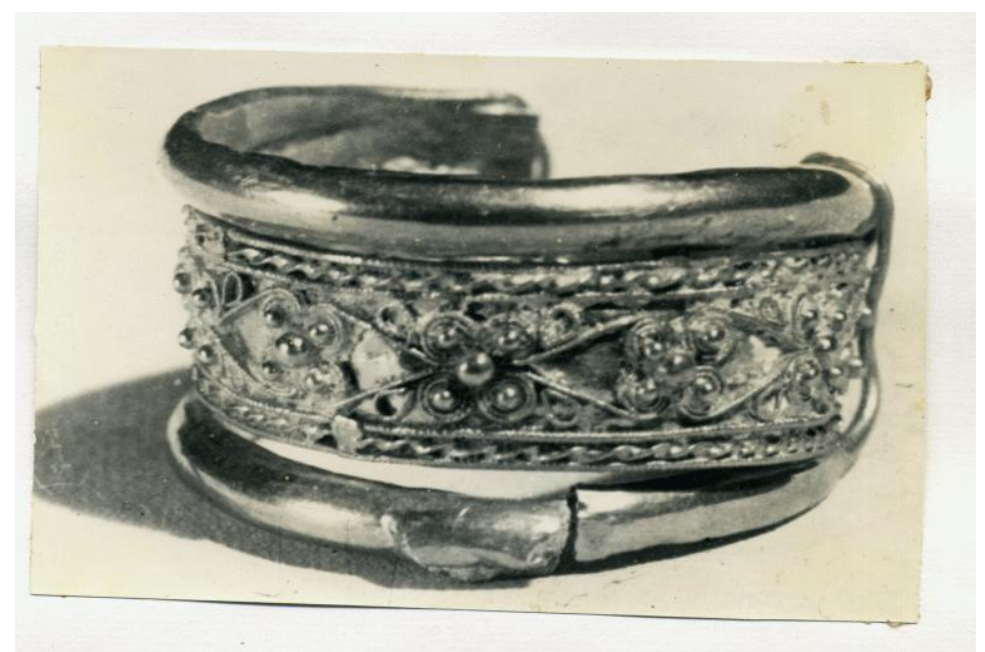

Fuente: Archivo de la Universidad de Cádiz (AUCA), C-4-21 JC

\subsection{Juegos y ajuar}

Son numerosos. Se pueden ver en las láms. XLII (Necrópolis); XLIII (glacis); XLIII (Instituto Nacional de Previsión). En el Museo de Cádiz se conserva el vaso biberón de época púnica, hallado en la Playa de Sta. $\mathbf{M}^{\mathrm{a}}$ del Mar, en la excavación dirigida por ella (lám. XIX y lám. XXVI en la caja 4-27).

Imagen 21. Vaso biberón púnico

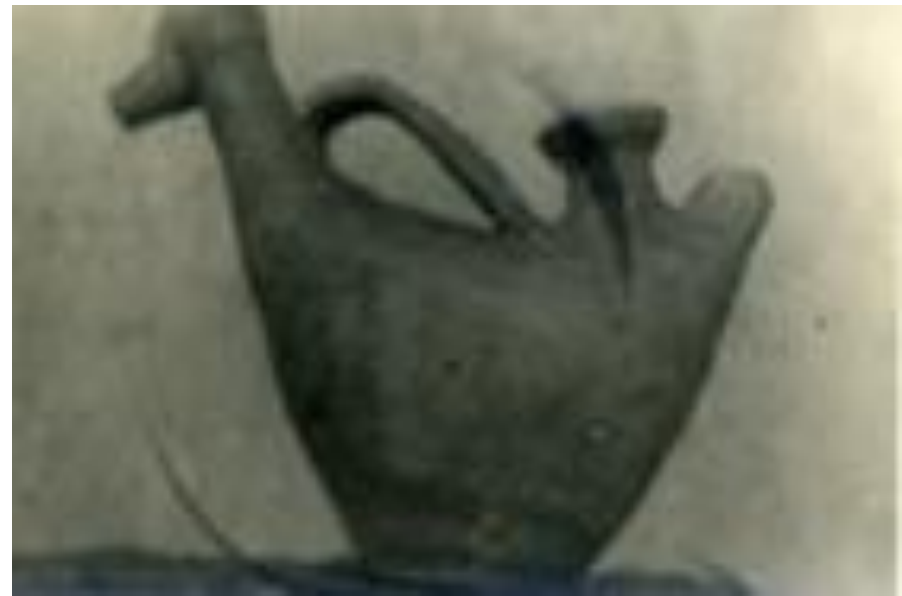

Fuente: Catálogo de la Biblioteca UCA. Colección Jiménez Cisneros

\subsection{Estampillas de lucernas}

DOI del artículo:

http://dx.doi.org/10.25267/Cuad investig fondos arch UCA.2019.i1

Editorial nd UCA .06 
Son muy numerosas: lám. XLVI. Merecería la pena el estudio de los temas representados en ellas ${ }^{19}$. Las hay con motivos animales, mitológicos, juegos gladiatorios, escenas de la vida diaria, motivos eróticos, geométricos, etc.

Imagen 16. Dibujos de estampillas con diversos motivos en lucernas.

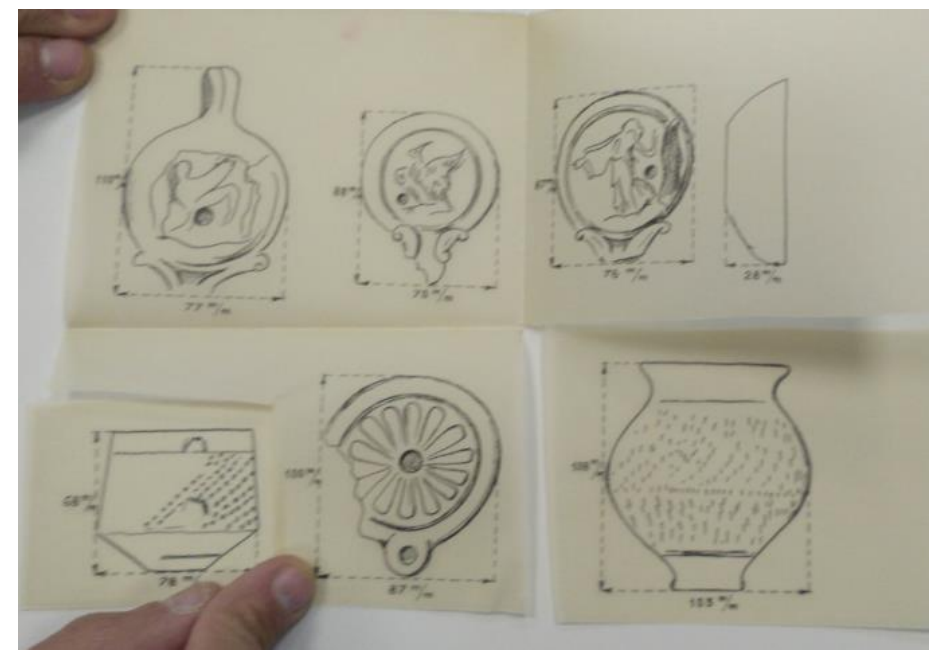

Fuente: Catálogo de la Biblioteca UCA. Colección Jiménez Cisneros

19 Pelayo Quintero (1945). "La colección de lucernas del Museo Arqueológico de Tetuán (Marruecos)", M. M.A. P., VI, Madrid 1945, págs. 208-214. L. Lagóstena, La producción de salsas y conservas en la Hispania romana, ss. II .C-VI d.C. Univ. Barcelona 2001. S. Gómez Carrión, Las lucernas de la Necrópolis de Gades, TFG. UCA, Cádiz 2015.

DOI del artículo:

http://dx.doi.org/10.25267/Cuad investig fondos arch UCA.2019.i1 